\title{
La Grama St. Augustine para Patios de Florida ${ }^{1}$
}

\author{
Laurie E. Trenholm, Marco Schiavon, J. Bryan Unruh, Travis W. Shaddox, Kevin E. Kenworthy, \\ Carlos Balerdi, y Henrique Mayer²
}

La grama o césped St. Augustine (Stenotaphrum secundatum [Walt.] Kuntze) está muy adaptada a las zonas calurosas y húmedas (subtropicales) del mundo. Se cree que es nativa de las regiones costeras del Golfo de México y del Mediterráneo. St. Augustine es la especie de grama más usada en Florida (Figura 1). Esta publicación está destinada a propietarios de casas y encargados de pasto y césped que manejan grama St. Augustine en el paisaje de Florida.

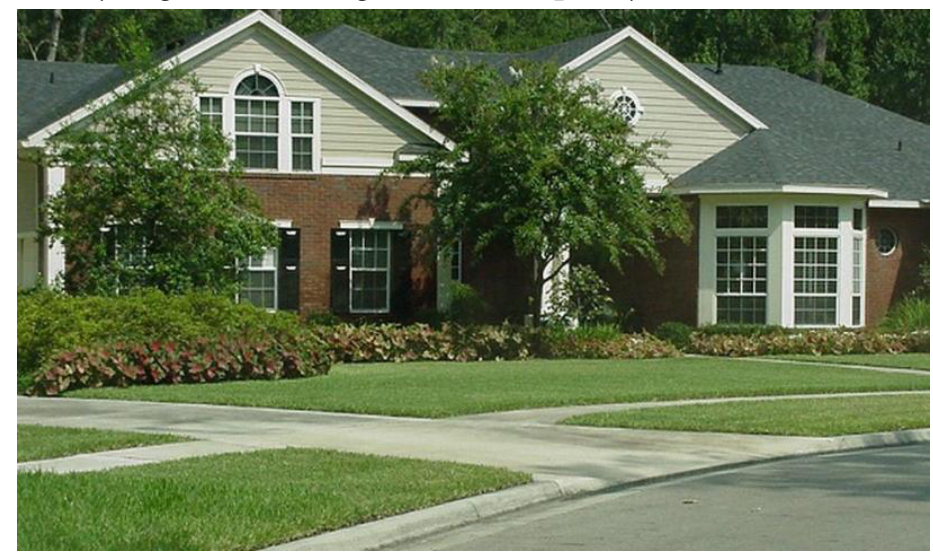

Figura 1. Grama St. Augustine en patios urbanos.

Credits: L. Trenholm, UF/IFAS

\section{Ventajas}

La grama St. Augustine tiene un color azul-verdoso, es densa y está bien adaptada a la mayoría de suelos y áreas climáticas de Florida. Tiene buena resistencia a la salinidad $\mathrm{y}$ algunas variedades resisten la sombra mejor que otras especies de césped adaptadas a zonas calurosas. La grama St. Augustine se establece rápida y fácilmente y se puede sembrar utilizando piezas cuadradas o rectangulares (sod), ramitas (springs), pedacitos o cuadritos (plugs).

\section{Desventajas}

La grama St. Augustine, como otras gramas tiene algunos problemas de mantenimiento y de plagas. Requiere agua para mantenerse verde y saludable y puede necesitar regadío suplementario durante largos períodos de sequía. Tiene muy poca tolerancia al "desgaste" o abuso y no aguanta el pisoteo o tráfico de vehículos. En algunas partes del estado de Florida entra en un periodo latente (dormancia) en el invierno tornándose amarillenta o bronceada, y el periodo dura hasta la primavera. Bajo mucha fertilización y regadío puede producir mucho acolchonamiento (thatch), lo que puede resultar en problemas de insectos u hongos. Tiene hojas anchas y tallos toscos o gruesos, por lo que no crece con la densidad que presentan otras especies. El mayor problema de la grama St. Augustine es la chinche sureña (chinch bug) (Blissus insularis Barber), que causa daños considerables si no se controla. Algunas variedades también son afectadas por enfermedades, como la mancha ceniza de la hoja (gray leaf spot) (Pyricularia grisea),

1. Este documento, ENH1288, es uno de una serie de publicaciones del Departamento de Horticultura Ambiental, UF/IFAS Extensión. Fecha de primera publicación: enero 2018. Revisado septiembre 2021. Visite nuestro sitio web EDIS en https://edis.ifas.ufl.edu.

2. Laurie E. Trenholm, retired professor, Environmental Horticulture Department; Marco Schiavon, assistant professor, turf \& sod, Environmental Horticulture Department, UF/IFAS Ft. Lauderdale Research and Education Center; J. Bryan Unruh, professor and associate center director, Environmental Horticulture Department, UF/IFAS West Florida REC; Travis W. Shaddox, former assistant professor of turfgrass, Environmental Horticulture Department, UF/IFAS Ft. Lauderdale REC; Kevin E. Kenworthy, professor, plant breeding and molecular genetics, Agronomy Department; C. Balerdi, professor emeritus; and H. Mayer, urban commercial horticulture agent, UF/IFAS Extension Miami-Dade County; UF/IFAS Extension, Gainesville, FL 32611.

The Institute of Food and Agricultural Sciences (IFAS) is an Equal Opportunity Institution authorized to provide research, educational information and other services

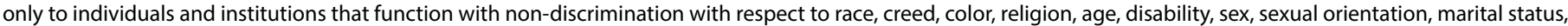

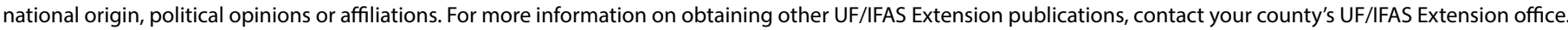
U.S. Department of Agriculture, UF/IFAS Extension Service, University of Florida, IFAS, Florida A \& M University Cooperative Extension Program, and Boards of County Commissioners Cooperating. Nick T. Place, dean for UF/IFAS Extension. 
mancha grande (large patch) (Rhizoctonia solani), y la pudrición de raíces (take-all root) (Gaeumannomyces graminis ver. Graminis). El control químico de malezas puede ser problemático, particularmente cuando hay que controlar malezas gramíneas, ya que existen pocos herbicidas para usar en patios urbanos.

\section{Cultivares}

Hay varios cultivares disponibles de St. Augustine para usar en Florida. Los cultivares varían en su tolerancia al estrés con el medio ambiente y a la susceptibilidad con las plagas. Los cultivares de St. Augustine se pueden agrupar de acuerdo a sus requerimientos con la altura de corte y por la textura de sus hojas. Los cultivares regulares se cortan de 3.5-4 pulgadas y los enanos deben cortarse a 2.5 pulgadas. La Tabla 1 da algunas características de crecimiento para los cultivares disponibles.

\section{Cultivares Regulares 'BITTERBLUE'}

'Bitterblue' fue seleccionado en los 1930s. 'Bitterblue' tiene una textura relativamente fina, densa y un color azul-verdoso intenso. Tiene buena tolerancia al frío y a la sombra y está bien adaptado para uso en todo el estado de Florida. Debe ser cortado a una altura de 3.5-4 pulgadas.

\section{'CLASSIC'}

'Classic' es una variedad patentada y puesta a la venta a principios de los 2000 por Woerner Turf. Tiene buena tolerancia al frío y es usado en toda la Florida y otros estados. No se ha verificado su tolerancia a la sombra por los investigadores universitarios y no hay evidencia de que sea superior a otros cultivares. Debe ser cortado a una altura de 3.5-4 pulgadas. Tiene un color verde intenso.

\section{'FLORATAM'}

'Floratam' (Figura 2) es una variedad de St. Augustine mejorada, que fue puesta a la venta conjuntamente por la Universidad de Florida y Texas A\&M. 'Floratam' es el cultivar de St. Augustine más producido y sembrado en Florida. Tiene una textura tosca, poca tolerancia al frío y a la sombra comparada con otros cultivares.

No se desarrolla ni persiste bien en lugares con menos de 6 horas de luz solar al día. Crece vigorosamente en la primavera y el verano. Cuando fue puesta inicialmente a la venta tenia buena resistencia documentada por la Universidad de Florida a la chinche sureña (Blissoos insularis). Desafortunadamente, ésta se ha perdido gradualmente y ahora la chinche es una plaga importante de 'Floratam'. Es susceptible a la mancha gris (Pyricularia grisea) y a otras enfermedades. 'Floratam' no tolera herbicidas que contienen atrazina cuando se aplica a temperaturas por encima de $85^{\circ} \mathrm{F}$. Debe ser cortada a una altura de 3.5-4 pulgadas. 'Floratam' puede desarrollar necrosis viral letal (NVL) de la infección del virus del mosaico de la caña de azúcar. Los síntomas de NVL empeoran las de virus del mosaico de la caña de azúcar: la coloración amarilla causada por el virus del mosaico de la caña de azúcar se convierte en marrón y mata al césped. Para aprender más sobre el virus del mosaico de la caña de azúcar, lean EDIS PP313, Mosaic Disease of St. Augustinegrass Caused by Sugarcane Mosaic Virus (https://edis.ifas.ufl.edu/publication/PP313)

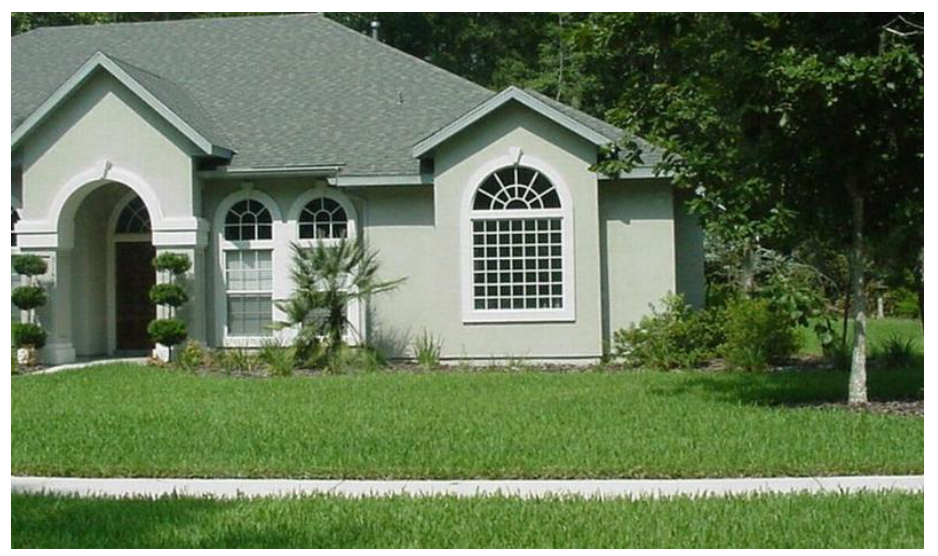

Figura 2. 'Floratam' en el jardín. Es la grama más utilizado en Florida. Credits: L. Trenholm, UF/IFAS

\section{'PALMETTO'}

'Palmetto' fue una selección encontrada por un productor de grama en Florida en 1988 y puesta a la venta a mediados de los 1990. A veces se le menciona como un cultivar semi-enano, con un hábito de crecimiento e internudos más cortos que muchos otros cultivares, pero es un poco más grande que las variedades de St. Augustine enanas. Crece bien al sol y en sombra parcial, pero no en sombra intensa. Algunas veces se le refiere como resistente a la sequía, pero las investigaciones indican que no tiene más tolerancia a la sequía que otros cultivares de St. Augustine. No es resistente a insectos y tiene algunas veces problemas con enfermedades, particularmente en el ambiente húmedo de Florida. Tiene tendencia a tener un color verde más claro que muchos otros cultivares. Debe ser cortado de 3-4 pulgadas de altura.

\section{'RALEIGH'}

'Raleigh' es resistente al frío y fue puesto a la venta por North Carolina State University en 1980. Tiene un color medio verdoso y una textura tosca. Es susceptible a la chinche y a la enfermedad conocida como mancha grande (Rhizoctonia solani), pero se usa en el Norte de Florida por su resistencia a temperaturas más bajas. Es altamente 
susceptible a la mancha gris (Pyricularia grisea). Durante los calores máximos del verano, 'Raleigh' se pone amarillo y crece menos que en temperaturas más frescas. Aplicaciones suplementarias de hierro pueden reducir la tendencia al amarillamiento. 'Raleigh' está mejor adaptada a suelos arcillosos pesados con el $\mathrm{pH}$ mediano a bajo del Norte y Noreste de Florida.

\section{‘PROVISTA'}

'ProVista' es un cultivar nuevo basado en las características comprobadas de 'Floratam.' 'ProVista' provee una buena cobertura del suelo y es el primer cultivar tolerante al herbicida glifosato que se encuentra en el mercado. Comparado con 'Floratam,' 'ProVista' tiene un color verde más oscuro, mejor tolerancia a la sombra y una lámina foliar igual de ancha. Además, 'ProVista' presenta un crecimiento más lento que 'Floratam' por lo que requiere ser cortado con una frecuencia menor.

\section{'CITRABLUE'}

'CitraBlue' es el nuevo cultivar desarrollado en la Universidad de Florida, ha estado disponible en el mercado desde 2018. Este cultivar presenta un color azul-verde lo que lo distingue fácilmente de los otros cultivares de St. Augustine (Figura 3). 'CitraBlue' posee crecimiento horizontal y más denso que 'Floratam. Gracias a estas características compite con las malezas mejor que 'Floratam'. Dado su crecimiento prostrado, 'CitraBlue' se puede cortar más corto que otros cultivares, sin embargo, el continuo crecimiento horizontal, y la producción de estolones puede causar más acolchonamiento. 'CitraBlue' es más resistente a la sequía que Floratam, Palmetto, y Raleigh y no parece afectarse tanto a las enfermedades. Dada su recién introducción en el mercado, la investigación de la Universidad de Florida se está enfocando en las mejores prácticas de manejo para este cultivar.

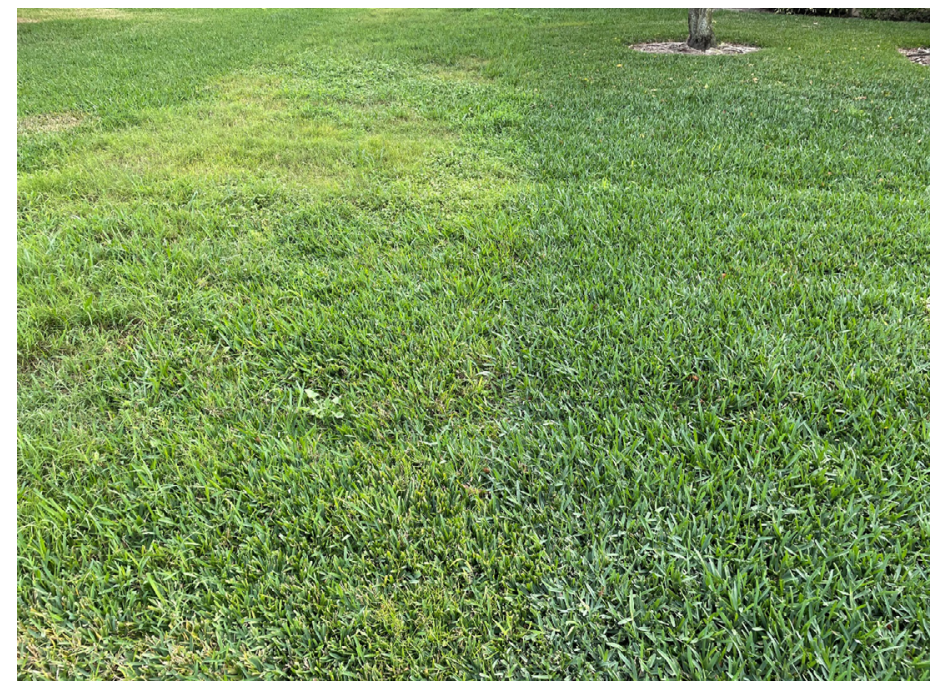

Figura 3. 'Floratam' (izquierda) y 'CitraBlue' (derecha)

Credits: Marco Schiavon, UF/IFAS

\section{Cultivares Enanos 'SEVILLE'}

'Seville' es un cultivar de hojas finas con color verde oscuro y un crecimiento rastrero. Es susceptible a la chinche y al gusano telarañero (Herpetogramma phaeopteralis) como otros cultivares enanos. 'Seville' tiende a formar acolchonamiento, crece bien en sombra y sol, pero es sensible al frío. No es tan común como 'Delmar' pero es una buena opción para lugares sombreados. 'Seville' debe cortarse a una altura 2-2.5 pulgadas.

\section{Establecimiento de la grama St. Augustine}

La grama St. Augustine puede sembrarse todo el año en las regiones calurosas de Florida, pero la mejor época de siembra para su establecimiento rápido es durante el tiempo de crecimiento activo. También es mejor evitar temperaturas extremas, especialmente si posibles temperaturas de congelación están anunciadas. En el Sur de Florida, el tiempo óptimo para el establecimiento es final del otoño, invierno o en primavera. Para el centro y Norte de la Florida, trate de evitar el establecimiento durante el invierno o en los meses calientes y secos del verano. El césped St. Augustine se establece sólo por propagación vegetativa, esto incluye piezas (sod), pedacitos (plugs) y ramitas (springs). La propagación vegetativa se realiza con parte de los puntos de crecimiento de la planta en vez de semillas. El césped St. Augustine tiene estolones (tallos encima del suelo) los cuales poseen áreas con células que se están dividiendo activamente en los nudos. Estas áreas son capaces de generar tallos nuevos y crecimiento de raíces, y son responsables del crecimiento lateral de la grama St. Augustine a lo largo del suelo.

Cuando la grama esta recién sembrada es importante regar utilizando un programa adecuado. Varios riegos cortos (5-10 minutos) durante todo el día por 7-10 días después de la siembra ayudan al césped a establecerse sin secarse. Por los siguientes 7-10 días riegue una vez aplicando $1 / 4-1 / 2$ pulgada de agua. Después de esto, la frecuencia debe reducirse a $2-3$ veces por semana, aplicando otra vez 1/4-1/2 pulgadas de agua. De 3-4 semanas después de la siembra la grama deberá estar completamente establecida y el riego se hará cuando se necesite. Para más información, refiérase a la publicación ENH9, Watering Your Florida Lawn (Riegue su césped en Florida) (https://edis.ifas.ufl. edu/lh025).

Un césped recién sembrado no debe fertilizarse hasta 30-60 días después de la siembra, ya que el sistema de raíces no 
está bien desarrollado. Fertilizar antes de éste periodo puede resultar en el lavado de nutrientes o acarreo y la potencial contaminación del suelo o agua superficial. Las piezas de grama (sod) son generalmente fertilizadas en la finca antes de ser cosechadas, por lo que no necesitan de fertilización suplementaria. El césped no deberá ser cortado hasta que las raíces hayan tenido tiempo de penetrar el suelo, lo que sucede generalmente de 14-21 días después de sembrarse. El enraizamiento se nota cuando el césped no puede ser levantado del suelo con fuerza. Para más información sobre la preparación del lugar y establecimiento, refiérase a ENH03, Establishing Your Florida Lawn (Estableciendo su césped en Florida) https://edis.ifas.ufl. edu/lh013.

\section{Siembra con Piezas Rectangulares (Sod)}

Esta operación es la forma más rápida de establecer el césped porque provee cubierta completa y no es necesario esperar hasta que el césped crezca y cubra el área. También reduce la competencia con malezas lo cual ocurre cuando se usan otros métodos de siembra cuando se dejan áreas descubiertas. Sin embargo, es importante entender que el césped es todavía vulnerable en esta etapa, y no está listo para pisarlo o jugar. El tiempo para establecerse depende del crecimiento y penetración de raíces en el suelo. Las piezas de césped deben ser colocadas como los ladrillos, sobre tierra descubierta en suelo húmedo, y los bordes deben ponerse apretados para evitar áreas descubiertas. El presionar con un cilindro y regar ampliamente garantizan buen contacto con el suelo para un enraizamiento rápido. Para más información sobre la preparación del suelo y la siembra refiérase a la publicación ENH02, Preparing to Plant a Florida Lawn (Preparación de la siembra de césped en Florida) (https://edis.ifas.ufl.edu/lh012).

\section{Siembra con Ramitas (Springs)}

La siembra con ramitas es más barata que la siembra con piezas, pero demora más para el establecimiento del césped. Las ramitas deben tener nudos y estolones, y se siembran en hileras separadas de 6-12 pulgadas. Los estolones se cubren con suelo, pero las hojas deben estar expuestas. El suelo debe presionarse y debe estar húmedo. El suelo debe estar húmedo hasta que las ramas y raíces comiencen a crecer.

\section{Siembra con Pedacitos o Cuadritos (Plugs)}

Algunos cultivares de St. Augustine están disponibles comercialmente como pedacitos o cuadritos en los centros de jardinería. Para hacer los cuadraditos se corta el césped en pequeños pedacitos. La distancia entre cuadraditos varia de 6-24 pulgadas. El espacio menor resulta en una cobertura más rápida y reduce la competencia con las malezas. Los cuadraditos se colocan en hoyos del mismo tamaño o en surcos abiertos y tapados en su lugar. Un buen riego completa la operación. El césped debe ser cuidado de igual forma que en el caso de la siembra con ramitas.

\section{Mantenimiento}

Las buenas prácticas de mantenimiento son el mejor medio para evitar plagas, problemas de estés y mantener saludable el césped. St. Augustine requiere fertilizantes para mantener una buena cobertura y crecimiento saludable. Durante ciertos meses del año, necesita riego. Se pueden minimizarse el uso de los pesticidas si otras prácticas de cultivo (corte, riego, fertilización) se hacen correctamente y se utilizan prácticas de manejo integrado de plagas (MIP).

\section{Nutrición}

La nutrición apropiada es importante para mantener un césped saludable. La fertilización y otras prácticas de cultivo influencian la salud general, calidad del césped y reducen la vulnerabilidad a muchos factores de estreses, como malezas, insectos y enfermedades. Es muy importante que cualquiera que fertilice el césped se familiarice y siga las mejores prácticas de manejo del programa Florida Friendly Landscaping ${ }^{\text {Th }}$ Best Management Practices (FFL, $\mathrm{BMP}$ ). Estas prácticas se diseñaron para mantener el césped saludable, así como reducir cualquier contaminación de los recursos hídricos ocasionados por el mal uso de los fertilizantes en patios. En el estado y en algunos condados y ciudades existen regulaciones locales que afectan la utilización de fertilizantes en el césped. Asegúrese de conocer estas regulaciones y de siempre seguir las instrucciones de la etiqueta del fertilizante. Para más información sobre las mejores prácticas de manejo por favor refiérase a la publicación ENH979, Homeowner Best Management Practices for the Home Lawn (https://edis.ifas.ufl.edu/ep236).

Un análisis de suelo debe hacerse para determinar el $\mathrm{pH}$ y la salinidad antes de la siembra o si se está comprando una casa con la grama ya sembrada. La oficina de Extensión local tiene instrucciones y materiales para tomar las muestras de suelo y para enviarlas al Extension Soil Testing Laboratory (Laboratorio de Análisis de Suelo de Extensión) para su análisis. Para más información sobre cómo obtener y enviar una muestra de suelo, consultar http://soilslab.ifas. ufl.edu/ESTL\%20Home.asp. 
Según las Reglas para la fertilización de césped en áreas urbanas de Florida [Florida Urban Turfgrass Fertilization Rule (Reglas para la fertilización de césped en áreas urbanas de Florida; (5E-1.003 F.A.C.)] permite la aplicación de hasta 2 lbs. de Nitrógeno por 1,000 pies cuadrados cuando se aplica el fertilizante en primavera o verano con un fertilizante depor lo menos un 65\% de nitrógeno de liberación controlada o lenta. No se pueden aplicar más de $0.7 \mathrm{lbs}$ de Nitrógeno soluble (de liberación rápida) por 1,000 pies cuadrados cada vez (https://edis.ifas.ufl.edu/ep535). Para información de cómo determinar la cantidad de fertilizante requerida, por favor refiérase a la publicación ENH962, Figuring Out Fertilizer for the Home Lawn (http://ufdc.ufl. edu/IR00003315/00001).

Como regla general, la primera aplicación de fertilizante en el año debe de ser a principios de abril en el Centro de la Florida y a mediados de abril en el Norte de Florida. En el Sur de Florida, pueden hacerse a través del año ya que el crecimiento ocurre durante todo el año. Las guías para fertilizar de la Universidad de la Florida, ofrecen una serie de cantidades por la cual una especie de césped en particular puede ser exitosamente mantenida en las diferentes regiones del estado. Estas cantidades incluyen el efecto que determinados microclimas locales puedan tener en el crecimiento del césped. Un ejemplo de esto sería un césped que este parcialmente a la sombra y al sol. La grama que crece en la sombra necesita menos fertilizante que una creciendo al sol. La fertilización está también afectada por el tipo de suelo, la materia orgánica y el manejo de los residuos de grama cortada (clippings). Adicionalmente, un césped nuevo en un suelo arenoso con poca materia orgánica requiere más fertilizante que uno que ha sido abonado por muchos años. En Florida, algunas casas y zonas nuevas pueden estar contiguas a zonas mucho más viejas, por lo que la misma cantidad de fertilizante pueda que no sea buena para todas. Estas guías proporcionan una cantidad de fertilizante básico donde el usuario puede iniciar un programa de fertilización. Es aconsejable que el usuario inicie un programa basado en las guías y lo ajuste de acuerdo a como responde el césped.

Las guías de fertilización dividen al estado en tres áreas geográficas como se ve en la Tabla 2. Las cantidades están en libras de Nitrógeno por 1000 pies cuadrados por año. Para calcular las cantidades correctas de fertilizante, por favor refiérase a la publicación ENH962, Figuring Out Fertilizer for the Home Lawn (http://ufdc.ufl.edu/ IR00003315/00001).

Dependiendo de la situación geográfica, el fertilizante debe aplicarse al césped St. Augustine en 2-6 aplicaciones desde la primavera hasta el otoño (o todo el año en el Sur de Florida). No se recomienda aplicar el fertilizante muy temprano durante la estación de crecimiento particularmente en el Norte de Florida porque una helada tardía puede dañar el césped y el sistema de raíces no estará completamente desarrollado en ese tiempo para asimilar los nutrientes. Igualmente, no fertilice muy tarde en el año después que el crecimiento haya disminuido.

Cuando el pH del suelo es superior a 7, o donde se riega con agua con $\mathrm{pH}$ elevado, la aparición de hojas amarillas pueden ser una indicación de falta de hierro o manganeso. Aplicaciones de materiales solubles o quelados pueden proveer un reverdecimiento en algunos casos. Es importante hacer notar que el hierro no es un substituto del nitrógeno, el cual provee las bases para el crecimiento y se necesita para la salud del césped. Mientras que las deficiencias de hierro y nitrógeno producen amarillamiento del césped, sus deficiencias son diferentes en las plantas. La aplicación de hierro no cura el amarillamiento debido a la deficiencia de nitrógeno y el hierro no es un substituto del nitrógeno. Abonos foliares de hierro como el sulfato de hierro o soluciones de quelato de hierro ayudan a aliviar las deficiencias de hierro y abonos de nitrógeno aplicados de acuerdo a las guías de UF/IFAS alivian las deficiencias de nitrógeno.

\section{Corte}

Prácticas apropiadas de corte son necesarias para tener un césped saludable y atractivo. Cultivares regulares de St. Augustine ('Bitterblue', 'Classic', 'Floratam', etc) cortadas con una cortadora de césped rotativa (Rotary mower) deben mantenerse a una altura de 3.5-4 pulgadas. Cortes continuados a alturas más bajas, aumentan el estrés en el césped, disminuyen el enraizamiento profundo, aumentan la posibilidad de dañar el césped, y puede aumentar la susceptibilidad a problemas de plagas (Figura 4). Mantener la altura apropiada ayuda al césped a tener un sistema de raíces profundas y da mejor apariencia al césped. No más de $1 / 3$ de las hojas deben de ser removidas en cualquier corte. Si es posible, la altura del corte debe ser aumentada durante periodos de estrés hídrico o si el césped crece en la sombra. Los cultivares enanos tienen un bajo hábito de crecimiento y deben ser cortados de 2-2.5 pulgadas. Cortar infrecuentemente o muy alto, así como el exceso de riego y de fertilizantes puede resultar en un aumento en la formación de acolchonamiento. Patios cortados con cortadoras automáticas (roboticas) pueden tolerar cortes mas bajos porque estas cortadoras remueven constantemente solo una porción muy pequeña de la lamina foliar y no causan daños. Investigación hecha en la Universidad 
de Florida demuestra que Floratam se puede cortar a 2.4 pulgadas durante todo el año sin consecuencias negativas.

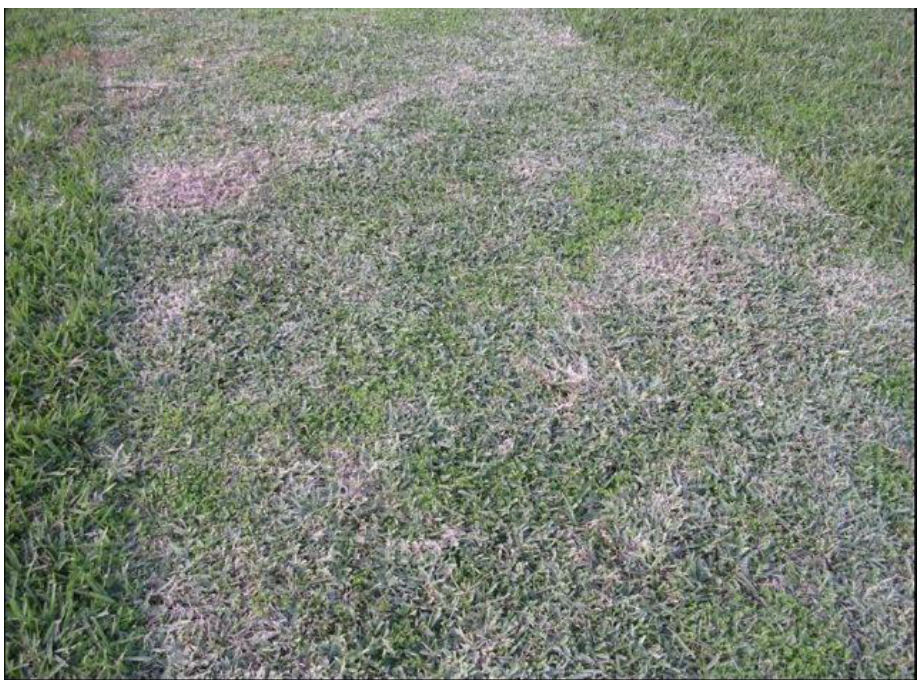

Figura 4. Grama dañada al ser cortado muy bajo. Siempre córtelo a la altura más alta recomendada para la especie y el cultivar.

Credits: L. Trenholm, UF/IFAS

Una cortadora de césped rotativa puede usarse en St. Augustine. Es importante mantener las cuchillas afiladas y bien ajustadas para hacer buenos cortes. Las cuchillas sin filo dejan el césped con un color marrón debido al desgarramiento de tejido que ocasionan al cortar irregularmente. Durante la estación de crecimiento, las cuchillas deben afilarse mensualmente. St. Augustine típicamente requiere cortes semanales durante la estación de crecimiento y menos cortes durante los meses fríos del año. En el Norte de Florida el corte puede no ser necesario durante los meses de invierno. Los desechos de grama cortada (clippings) se deben dejar en el césped cuando se corta a la altura y frecuencia apropiadas. Bajo estas condiciones los desechos de cortes no contribuyen al acolchonamiento.

Los desechos añaden nutrientes y materia orgánica al suelo. Si hay demasiada acumulación de desechos cortes (por ej. hay abultamiento), se recomienda dejarlos secar y dispérselos uniformemente por el césped.

\section{Riego}

Regar en base a "cuando se necesita" es la mejor manera de mantener cualquier césped establecido y adulto, siempre que se aplique la cantidad de agua apropiada. El riego se necesita cuando las hojas comienzan a doblarse, marchitarse o ponerse de un color azul-grisáceo, o cuando la marca de los pies se ven al caminar sobre el césped (Figura 5). Aplicar $1 / 2-3 / 4$ pulgadas de agua por aplicación. Esto moja aproximadamente las 8 pulgadas superiores del suelo donde están la mayor cantidad de las raíces. Siga las restricciones locales de riego.

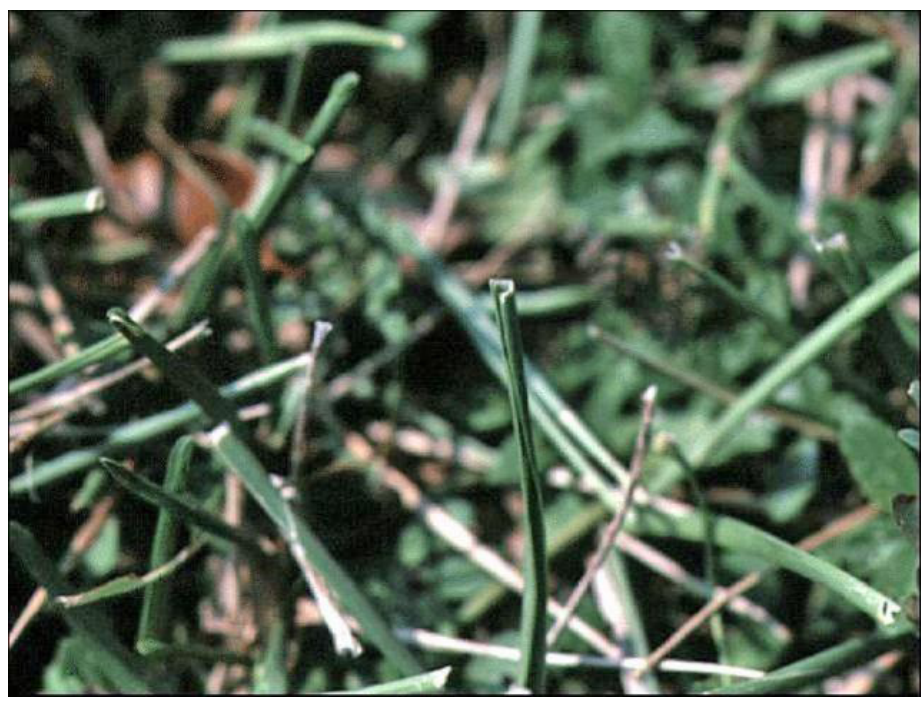

Figura 5. Deje que la grama le indique cuando regar. Busque hojas dobladas como se ve en la foto.

Credits: L. Trenholm, UF/IFAS

Para determinar el tiempo adecuado de riego para suministrar la cantidad de agua adecuada, coloque varios recipientes cilíndricos con lados rectos (por ej.: latas de atún o de comida de gatos) a través de la zona a regar, riegue cada zona para determinar cuánto tiempo pasa para llenar los recipientes hasta 1/2-3/4 pulgadas, apunte el tiempo transcurrido. Cada zona probablemente usará tiempos distintos para aplicar la misma cantidad de agua. Programe los tiempos para cada zona utilizando el reloj del sistema de riego automático. Si la variación en los recipientes es alta, necesita examinar mejor el sistema para mejorar la uniformidad. Refierase a la publicación ENH61, How to Calibrate Your Sprinkler System (http://ufdc.ufl.edu/ IR00003389/00001).

La frecuencia de riego cambiará por estación, menos agua se necesitará en el otoño e invierno. La cantidad aplicada no se debe ajustar, sólo la frecuencia. Para más informaciones sobre las practicas recomendadas para regar el césped, por favor refiéranse a ENH9, Watering Your Florida Lawn (https://edis.ifas.ufl.edu/lh025) y ENH63, Let Your Lawn Tell You When to Water (https://edis.ifas.ufl.edu/ep054). Las prácticas apropiadas de riego ayudan a mantener un césped saludable con menos estrés y problemas de insectos. Si las enfermedades mancha grande o la mancha gris de las hojas son un problema continuo, el exceso de riego o de nitrógeno, pueden ser los responsables. Algunas malezas como dollarweed y sedges crecen en suelos continuamente mojados. 


\section{Manejo de Plagas}

\section{Malezas}

La mejor manera para controlar las malezas es tener un césped saludable y vigoroso. Los problemas de malezas en el césped indican que éste se ha debilitado por prácticas de manejo impropias o por daños de plagas. Prácticas apropiadas de manejo pueden eliminar muchos problemas de malezas. Si las malezas son un problema continuo, deberán usarse herbicidas aprobados específicamente para St. Augustine. Si se necesita un herbicida pre emergente (por ej.: pendimethalin, benefin, bensulide, atrazina u otros) se pueden aplicar para controlar crabgrass (Digitaria sanguinalis) sí estuvo presente en otros años. La oportuna aplicación es crítica para un exitoso control. Por regla general, herbicidas pre-emergentes para controlar crabgrass (D. sanguinalis) se deben aplicar el 1 de febrero en el Sur de Florida, 15 de febrero en el Centro de Florida y del 15 de marzo en el Norte de Florida. Los herbicidas preemergentes no controlarán malezas que crecen activamente.

Los herbicidas post emergentes (e.j. Atrazina) deben ser aplicados cuando se necesiten para controlar las malezas anuales de verano, las perennes de hoja ancha y las gramíneas. Estos herbicidas no se deben aplicar si el césped tiene estrés hídrico o cuando las temperaturas del aire exceden $\operatorname{los} 85^{\circ} \mathrm{F}$. Su oficina local de Extensión puede asistirlo con la identificación de las malezas y proveerle con las últimas recomendaciones.

Muchas formulaciones comerciales de "fertilizantes/ herbicidas" proveen control, pero tienen que ser usadas con cuidado porque algunas plantas no los toleran. Estos herbicidas pueden dañar plantas del patio cuyas raíces se extienden mucho más allá debajo del césped. Estos materiales sólo deben usarse cuando exista una población uniforme de malezas. Si las malezas están sólo en una parte del césped, productos "herbicidas/fertilizantes" no se deben aplicar a todo el césped. Si la situación requiere, el uso de productos "fertilizante/herbicida" es importante determinar si la cantidad recomendada por el fabricante, suplir la cantidad de fertilizante necesitada por el césped y la cantidad de herbicida que se requiere para controlar la maleza. Más aplicaciones de fertilizante o herbicida pueden necesitarse para el control de malezas. Aplicaciones suplementarias de abono o herbicida pueden necesitarse si el "fertilizante/herbicida" no suple suficiente fertilizante para satisfacer el abono necesitado por el césped o de la cantidad de herbicida necesitada para controlar malezas. Lea cuidadosamente la etiqueta antes de usar el producto y siga todas las instrucciones. Para más información refiérase a la publicación EHN884, Weed Management in Home Lawns (https://edis.ifas.ufl.edu/ep141).

\section{Insectos}

La plaga más seria de St. Augustine es la chinche sureña Blissus insularis (Figura 6). Las chinches se alimentan del follaje chupando savia de las plantas a través de un pico en forma de aguja causando manchas amarillas-carmelitas en el césped (Figura 7). Las áreas afectadas se notan primero cuando el tiempo empieza a calentar en áreas a lo largo de aceras, cerca de edificios, y en áreas con estrés hídrico donde la grama está al pleno sol.

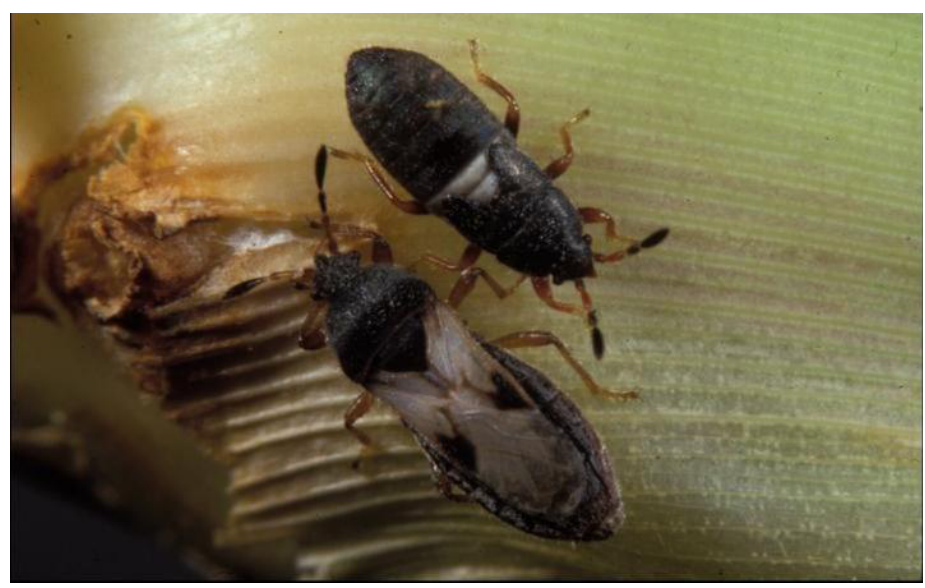

Figura 6. Adultos de chinche sureña Blissus insularis.

Credits: L. Buss, UF/IFAS

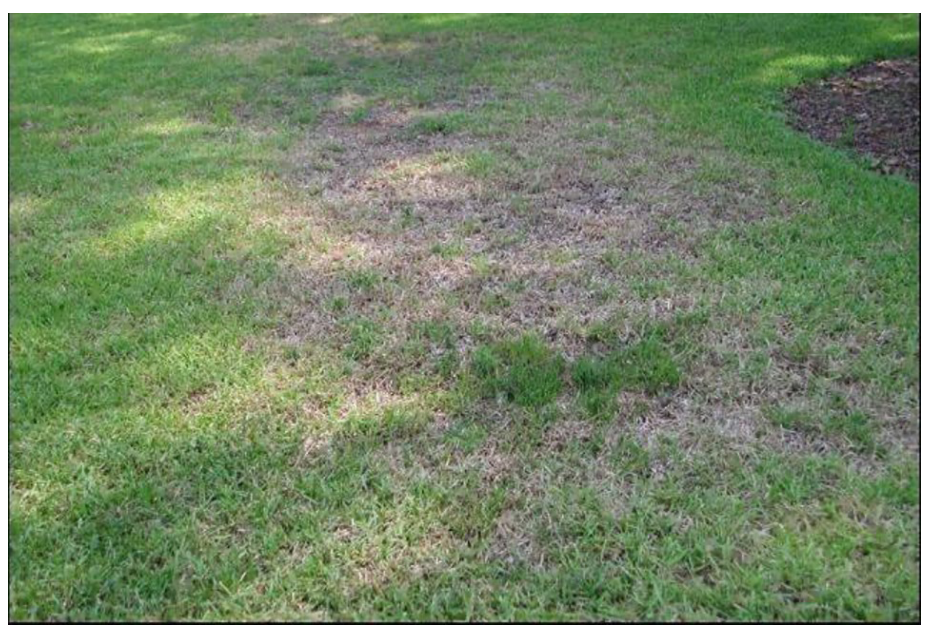

Figura 7. Daño causado por chinche sureña.

Credits: L. Buss, UF/IFAS

Compruebe si hay chinches quitando los extremos de una lata de café, insertando un extremo en el suelo en el margen de las áreas que se sospecha que están dañadas y llenándolo con agua. Después de 5 minutos, laschinches sureñas flotaran en la superficie del agua. En las áreas donde la chinche sureña es un problema serio, una única aplicación de insecticida podría ofrecer solo un control temporáneo, por lo que aplicaciones repetidas podrían ser necesarias. Muchas aplicaciones de insecticidas piretroides pueden 
ocasionar que algunas poblaciones de insectos desarrollen resistencia a los insecticidas piretoides sintéticos.

Otras plagas de insectos, que incluyen el gusano telarañoso telarañoso (Herpetogramma phaeopteralis), gusano soldado (Spodotera spp.), grillo-topo de césped (Scapteriscus spp.), y el gusano medidor (Mocis spp.) los que pueden dañar el césped St. Augustine. Los grillo-topos dañan áreas del césped creando túneles o lomitas flojas mientras buscan alimentos. Más daño puede resultar cuando pequeños animales y aves escarban al suelo en busca de ellos como alimento. Busque los topos examinando un área con túneles o aplicando 2 galones de agua mezclados con 1.5 onzas de detergente líquido por 2 pies cuadrados en áreas sospechosas. Los topos saldrán a la superficie en unos minutos.

Las larvas de los escarabajos blancos (Phyllophaga spp.) son otra plaga de St. Augutine. Se localizan al levantar el césped 2 pulgadas. Estas larvas se pueden ver alimentándose de las raíces. Para más información de control de insectos ver ENY300, Insect Pest Management on Turfgrass (https://edis. ifas.edu/ig001).

\section{Enfermedades}

La mancha grande (Rhizoctonia solani) (Figura 8) y la mancha gris (Pyricularia grisea) de las hojas (Figura 9) son dos importantes enfermedades de St. Augustine. La mancha grande afecta en tiempos calurosos y húmedos y es peor con exceso de nitrógeno. Se nota más en los meses de primavera y otoño. La mancha gris de las hojas se nota más en época de lluvias en el verano y causa más problemas al crecimiento nuevo. Ambas enfermedades pueden ser controladas con fungicidas.

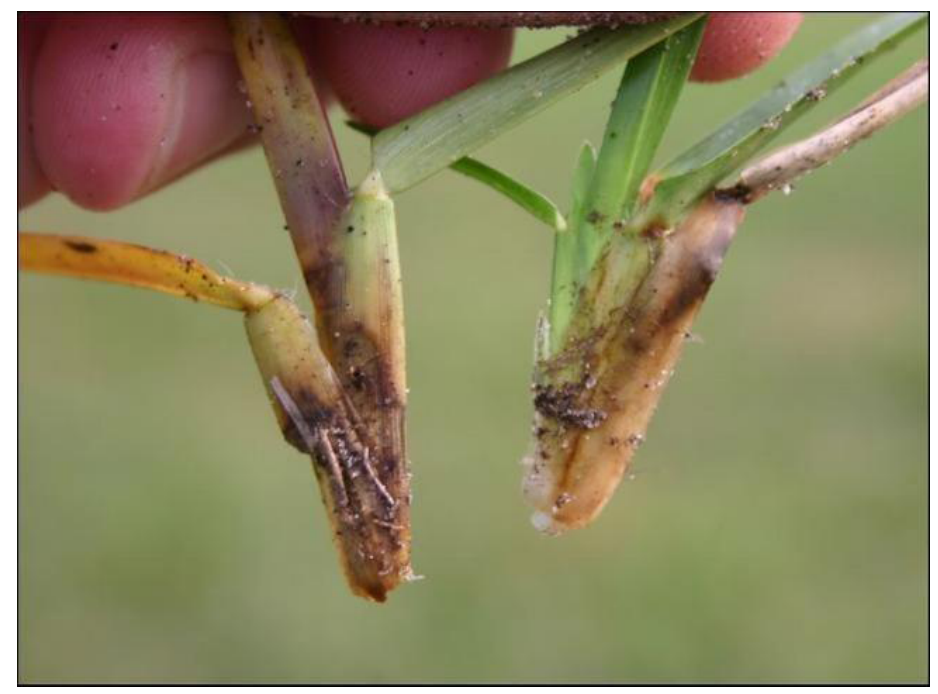

Figura 8. Síntomas de mancha grande (Rhizoctonia solani) en St. Augustine.

Credits: P. Harmon, UF/IFAS

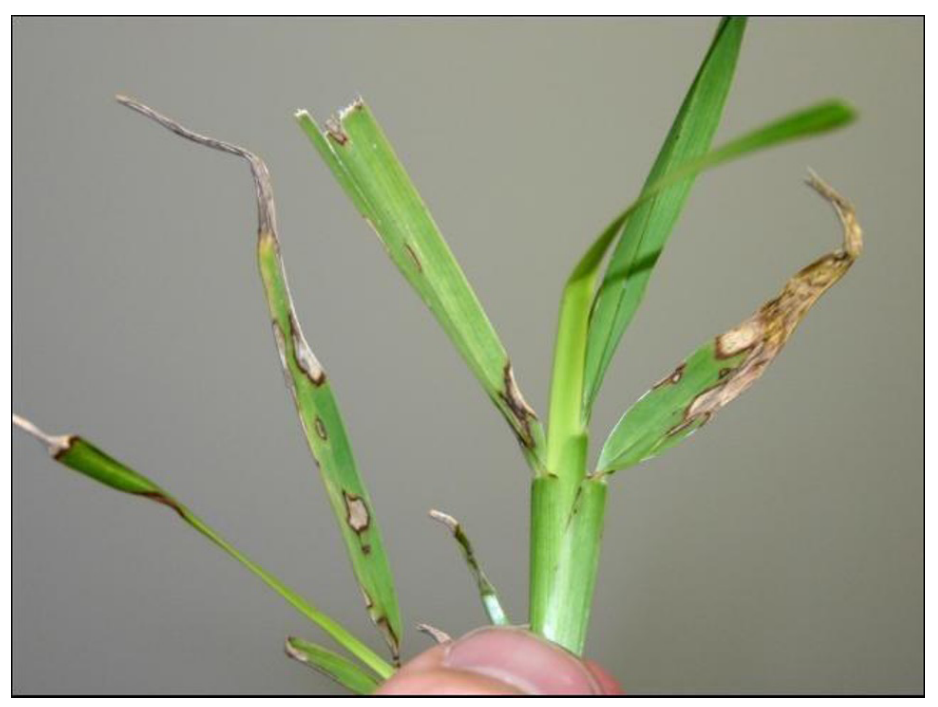

Figura 9. Síntomas de mancha gris (Pyricularia grisea) en St. Augustine. Credits: P. Harmon, UF/IFAS

Otros problemas de enfermedades en St. Augutine se originan en el sistema de raíces. Gaeumannomyce graminis var. Gramini (pudrición de raíces) progresa con alta humedad o en condiciones estresantes. Cuando los síntomas se notan arriba del suelo, la enfermedad está en estado avanzado. Seguir prácticas culturales apropiadas es la mejor defensa contra esta enfermedad. Ver SS-PLP-14, Turfgrass Disease Management (https://edis.ifas.ufl.edu/lh040), para más información.

\section{Nemátodos}

Varios tipos de nemátodos atacan al césped St. Augustine. La población de nemátodos es máxima a fines de abril y principios de mayo y otra vez a fines de Agosto y principios de Septiembre. Los síntomas de daño (Figura 10) incluyen pobre densidad, menos crecimiento, débil sistema de raíces, lenta recuperación después de lluvia o de riego y ciertas malezas tales como spurge (Chamaesyce spp.) y Florida pusley (Richardia scabra). Los niveles de nemátodos parásitos se identifican sólo por laboratorios. El servicio local de Extensión puede proveer información sobre cómo preparar las muestras de suelo al University of Florida Nematode Assay Laboratory. Hay opciones para el control de nemátodos para usar en el césped de casas, pero son caros. Los controles culturales son favorecer el desarrollo de raíces profundas elevando la altura de corte, regar menos frecuentemente pero más profundo y proveer bastante potasio al suelo. Para más información sobre nemátodos, referirse a ENY006, Nematode Management in Residential Lawns (https://edis.ifas.ufl.edu/ng039). 


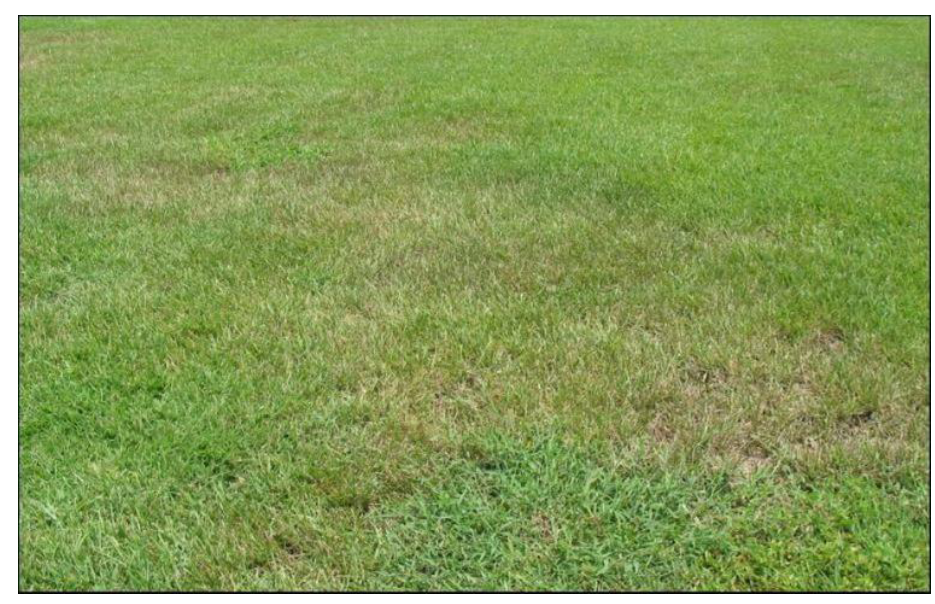

Figura 10. Signos de nemátodos en grama St. Augustine. Credits: W. Crow, UF/IFAS

\section{Otros Problemas}

Otros factores también pueden disminuir la calidad de un césped. Sombra excesiva, suelo compactado, mucha o poca agua, corte inapropiado, tráfico, y $\mathrm{pH}$ alto o bajo, todos pueden causar un desarrollo pobre del césped. Es importante reconocer el origen de un problema y corregirlo si es posible. Para más información sobre estos estreses ver ENH153, Environmental Stresses and Your Florida Lawn (https://edis.ifas.ufl.edu/ep070).

\section{Removiendo el Acolchonamiento}

El acolchonamiento es una capa de estolones, raíces, hojas no descompuestas mezclada con suelo (Figura 11). Dejar recortes sobre el césped no causa el acolchonamiento porque los cortes son descompuestos por microbios en el suelo. La formación de acolchonamiento es máxima en grama que es fertilizada o regada excesivamente.

Demasiado acolchonamiento reduce la penetración de agua y puede restringir la absorción de fertilizantes o pesticidas. En casos graves, las raíces pueden verse creciendo sobre el suelo y enraizando en la capa del acolchamiento. Este no es saludable y deja al césped vulnerable a muchos estreses.

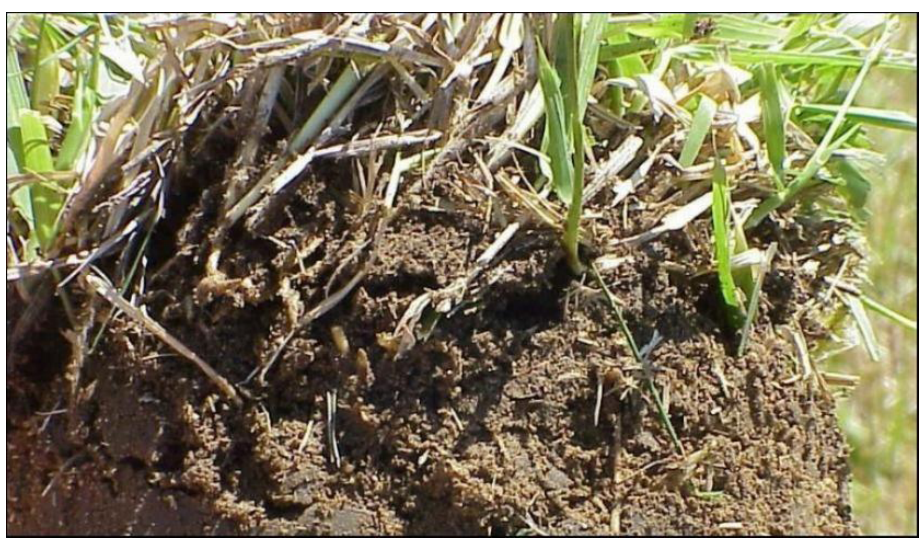

Figura 11. Acolchonamiento presente en St. Augustine, se forma especialmente cuando se aplica mucho fertilizantes y riego. Credits: J. B. Unruh, UF/IFAS
Si la capa acolchonada excede una pulgada, puede removerse cortando verticalmente ("verticutting") al principio de la primavera hasta mediados de verano. Estos cortes usan hojas verticales de corte que atraviesan el acolchado y un poco el suelo, lo que resulta en que mucho material muerto será removido de la superficie del césped. Un espacio de 3 pulgadas entre las hojas para descolchonar es mejor para St. Augustine. Precaución: cortar verticalmente puede resultar en daño al césped que requiere un período de recuperación. No intente el corte vertical a no ser que la grama esté creciendo activamente. El corte vertical debe ser hecho de Este a Oeste y de Norte a Sur, pero no en las cuatro direcciones. Los restos deben ser quitados rastrillando, barriendo o con aspiradoras, seguido por un corte convencional para mejorar la apariencia del césped y regar inmediatamente para prevenir deshidratación de la zona de raíces. Una semana después del corte vertical, se aplicará fertilizante a razón de $1 / 2$ libra de nitrógeno por 1,000 pies cuadrados para ayudar la recuperación. Este material debe de ser regado inmediatamente para pervertir quemar la grama. Aplicar una capa de suelo (top dressing) periódicamente encima del césped con $1 / 2$ pulgada de suelo similar al que está debajo del césped es un buen método de aliviar acumulación de acolchamiento. Sin embargo, esta labor requerida limita la practicabilidad de este método para la mayoría de los propietarios de casas. Si la capa de suelo es aplicada, el suelo debe estar libre de semillas de malezas y nemátodos y use precaución para no exceder la cantidad recomendada.

\section{Renovación}

Áreas grandes al descubierto, pueden ser replantadas usando ramitas al voleo ( 1 bushel per 1,000 pies cuadrados), por trocitos de 2 pulgadas cada 12 pulgadas o por piezas rectangulares. Estas áreas deben de estar húmedas siempre. Esto se logra mediante riegos ligeros y frecuentes varias veces al día hasta que los estolones se desarrollen o el césped esté enraizado. Con el tiempo, la frecuencia de riego debe ser gradualmente reducida pero la duración debe ser aumentada para aplicar 1/2-3/4 pulgadas de agua. Ver ENH03, Establishing Your Florida Lawn (https://edis.ifas. ufl.edu/lh013), para más información. 
Tabla 1. Características de crecimiento relativo de cultivares de St. Augustine.

\begin{tabular}{|l|l|l|l|l|l|l|l|}
\hline \multicolumn{1}{|c|}{ Cultivares } & $\begin{array}{c}\text { Altura de corte } \\
\text { (pulgadas) }\end{array}$ & \multicolumn{1}{|c|}{ Densidad } & \multicolumn{1}{|c|}{$\begin{array}{c}\text { Tolerancia al } \\
\text { frio }\end{array}$} & $\begin{array}{c}\text { Tolerancia a } \\
\text { sombra }\end{array}$ & $\begin{array}{c}\text { Chinch bug } \\
\text { resistance }\end{array}$ & $\begin{array}{c}\text { Resistencia } \\
\text { a chinches }\end{array}$ \\
\hline 'Bitterblue' & $3.5-4.0$ & Buena & Buena & Buena & Ligera & Oscuro \\
\hline 'CitraBlue' & $2.0-3.0$ & Muy buena & Adecuada & Muy buena & Ligera & Azul-verde \\
\hline 'Classic' & $3.5-4.0$ & Buena & Buena & Muy buena & Desconocida & Oscuro \\
\hline 'Floratam' & $3.5-4.0$ & Adecuada & Poor & Adecuada & Ligera & Oscuro \\
\hline 'Palmetto' & $3.0-4.0$ & Buena & Muy buena & Muy buena & Muy buena & Verde claro & Mediana \\
\hline 'ProVista' & & Adecuada & Adecuada & Very good & Desconocida & Oscuro \\
\hline 'Raleigh' & $3.0-4.0$ & Poca & Muy buena & Buena & Mala & Medium green & Tosca \\
\hline 'Seville' & $2.0-2.5$ & Muy buena & Adecuada & Muy buena & Desconocida & Oscuro & Fina \\
\hline
\end{tabular}

Tabla 2. Recomendaciones de fertilización anual para grama St. Augustine en tres regiones de Florida.

\begin{tabular}{|l|c|}
\hline \multicolumn{1}{|c|}{$\begin{array}{c}\text { Localización* } \\
\text { Norte de Florida }\end{array}$} & $\begin{array}{c}\text { Guía de fertilización con N } \\
\text { (Libras de N/1000 pies cuadrados por año) }\end{array}$ \\
\hline Centro de Florida & $2-4$ \\
\hline Sur de Florida & $2-5$ \\
\hline $\begin{array}{l}* \\
\text { SFlorida Norte_De Ocala hacia el Norte; Centro-Del Sur de Ocala hasta una línea que va de Vero Beach a Tampa; Sur- todo lo que queda al }\end{array}$ \\
\hline
\end{tabular}

